\title{
Research on Green Innovation of the Great Changsha-Zhuzhou-Xiangtan City Group Based on Network
}

\author{
Lu Wang ${ }^{1}$, Wenzhong Ye ${ }^{1}$ and Lingming Chen ${ }^{1,2, * \mathbb{D}}$ \\ 1 School of Business, Hunan University of Science and Technology (HNUST), \\ Xiangtan 411201, China; 19011501016@mail.hnust.edu.cn (L.W.); 1300030@hnust.edu.cn (W.Y.) \\ 2 School of Economics and Management, Xinyu University (XYU), Xinyu 338004, China \\ * Correspondence: lingming1016@mail.hnust.edu.cn; Tel.: +86-158-7009-2285
}

Citation: Wang, L.; Ye, W.; Chen, L. Research on Green Innovation of the Great Changsha-Zhuzhou-Xiangtan City Group Based on Network. Land 2021, 10, 1198. https://doi.org/ $10.3390 /$ land 10111198

Academic Editors: Luca Salvati, Iwona Cieślak and Andrzej Biłozor

Received: 5 October 2021

Accepted: 3 November 2021

Published: 5 November 2021

Publisher's Note: MDPI stays neutral with regard to jurisdictional claims in published maps and institutional affiliations.

Copyright: (c) 2021 by the authors. Licensee MDPI, Basel, Switzerland. This article is an open access article distributed under the terms and conditions of the Creative Commons Attribution (CC BY) license (https:// creativecommons.org/licenses/by/ $4.0 /)$.

\begin{abstract}
This article aims to promote the high-quality development of the Great Changsha-ZhuzhouXiangtan City Group and improve the green innovation efficiency of urban agglomeration. This article takes green innovation in networked urban agglomerations as its research subject. Furthermore, it analyzes the impact of network structure characteristics such as network scale and network structure hole on green innovation in urban agglomerations. Moreover, this study uses the unexpected output SBM model to measure green innovation efficiency of the eight prefecture-level cities in the Great Changsha-Zhuzhou-Xiangtan City Group from 2012 to 2018 and analyzes its influencing factors using the panel Tobit model. The results show that the overall green innovation efficiency of the Great Changsha-Zhuzhou-Xiangtan City Group is stable. The distribution of urban green innovation efficiency in the region is characterized by urban gradient and mid-stream drive. In the process of networked innovation, economic development, which has a positive impact on green innovation, promotes the overall effectiveness of the network structure. The low efficiency of urban educational resources, which has a negative impact on green innovation, leads to the redundancy of a network scale. The unapparent advantage of industrial structures, which have a negative impact on the development of green innovation, leads to the insufficient depth and breadth of network openness. Lastly, government support and the level of infrastructure have no impact on green innovation.
\end{abstract}

Keywords: Great Changsha-Zhuzhou-Xiangtan City Group; green innovation; network structure; unexpected output SBM model

\section{Introduction}

The Fifth Plenary Session of the 19th Central Committee of the Communist Party of China put forward a new goal of promoting green development and the harmonious coexistence between humans and nature. To launch the new development policy, the power institution proposed that the regional economic development takes green innovation as the new driving force, protects the environment, and considers the overall economic development situation to achieve sustainable economic growth. Due to the economic growth resulting from the traditional extensive economic development model, China is facing problems related to resource shortage, environmental pollution, and ecological destruction. The realization of sustainable economic and social development has become the focus of scholars. In the traditional economic and social development model, the model of high energy consumption and high pollution in exchange for economic benefits has caused damage to the ecological environment. Ignoring the environmental benefits generated by innovation behavior is not conducive to sustainable development. It is important to overcome the barriers of the traditional development model, take green innovation as the core driving force, and realize the leap of economic development and innovation. Green innovation is also known as environmental innovation, ecological innovation, or sustainable innovation. Compared with traditional innovation, green innovation aims at reducing environmental impact, achieving economic development while reducing resource 
consumption and environmental costs, which is beneficial to building an efficient and green economic and social development environment.

Urban agglomerations are the main form of the global division of labor, new urbanization, and rural revitalization. In the context of China entering a new era, urban agglomerations face problems such as the continued expansion of population and infrastructure construction scale, prominent contradictions in the economy, resources, environment, and increased pressure on urban bearing. To fully implement the Outline of Changsha-ZhuzhouXiangtan Regional Integrated Development Planning, we argue for providing full play to the driving role of Changsha-Zhuzhou-Xiangtan in implementing the strategy of "Three High and Four $\mathrm{New}^{\prime \prime}$, improving the speed of urban development, and striving to build a modern city with harmonious coexistence between humans and nature. At the same time, we should improve the linkage mechanism of ecological environment co-protection, jointly solve environmental pollution problems, jointly protect the Changsha-Zhuzhou-Xiangtan ecology, and strive for the Changsha-Zhuzhou-Xiangtan national ecological civilization pilot zone. The construction of the Changsha-Zhuzhou-Xiangtan metropolitan area is a significant achievement contributing to the rise of central China and the development of the Yangtze River Economic Belt. In September 2020, General Secretary Xi Jinping visited Hunan and emphasized that the integrated development of Changsha, Zhuzhou, and Xiangtan should continue achieving exceptional results and insisted on leading innovation and green growth. Thus, we intend to research green innovation and its influencing factors in the Great Changsha-Zhuzhou-Xiangtan City Group.

The article is arranged as follows: Section 2 presents the literature review; Section 3 introduces the theoretical mechanism, including the effect of network structure characteristics on green innovation in the urban agglomeration, and the influencing mechanism of green innovation in the Great Changsha-Zhuzhou-Xiangtan City Group based on a network of green innovation in the urban agglomeration. Section 4 introduces the model methodology and variable selection, including the index system and the selection of the index. Section 5 uses the unexpected output SBM model to measure the efficiency of green innovation. Section 6 uses data from the Great Changsha-Zhuzhou-Xiangtan City Group (from 2012 to 2018) to empirically analyze the impact of network structure on green innovation, and test its theoretical mechanism. Section 7 summarizes the conclusions and makes recommendations, and proposes future research directions.

\section{Literature Review}

An urban agglomeration is a vital innovation space and carrier. Some scholars have constructed the innovation cooperation network model among urban agglomerations to optimize the innovation strategy of urban agglomerations [1-3]. At present, many scholars are investigating the relationship between urban agglomeration and innovation performance of the network structure. For example, Sheng Yanwen et al. [4] used social network analysis and the DEA model to analyze the impact of central position, intermediary position, and structural holes of urban agglomeration innovation network on innovation efficiency. Ren [5] constructed a regional innovation network system to explore the impact of network size, network openness, structural holes, strong ties, and weak ties on innovation capability. Other scholars, based on stochastic frontier analysis [6], data envelopment analysis [7], or canonical correlation analysis [8], analyzed the impact of network size, network openness, network structure holes, and network density on regional innovation.

Research on green innovation primarily includes the concept definition, index measurement, and driving factors. So far, scholars in various countries have gained a profound understanding of the concept of green innovation [9,10]. For example, Kemp [11] argued that green innovation is an activity directed toward reducing environmental pollution and resource waste. The methods commonly used for green innovation efficiency are generally divided into parametric methods and non-parametric methods, such as stochastic frontier analysis and data envelopment analysis (DEA) [12,13]. Meanwhile, there are two standard methods for green innovation evaluation: One is to construct the evaluation index of green 
innovation [14] and the other is to use data envelopment analysis (DEA). For example, Tone [15] proposed the non-angle and non-radial DEA-SBM model, which solves the slack variables problem that the traditional model does not consider. Teng [16] verified the spatial correlation of green innovation development among cities in the Yangtze River Delta by combining the Super-SBM model with the GML index. The drivers of green innovation are mainly economic development [17], government support [18], and policy system considerations [19].

Green innovation research of the Changsha-Zhuzhou-Xiangtan urban agglomeration is mainly from green ecology and development, including: to evaluate the safety of the ecosystem of Changsha-Zhuzhou-Xiangtan urban agglomeration [20], to protect and construct green heart ecology [21], and to research the relationship between the construction of a two-oriented society ' comprehensive reform area and promote regional green development [22].

Compared with simply studying the green innovation of urban agglomerations, it is more appropriate to study the green innovation effect of the Changsha-Zhuzhou-Xiangtan City Group. In general, most of the existing literature suggests that green innovation can influence regional innovation development; however, conclusions based on the green innovation effect are not uniform. Moreover, the literature ignores the internal mechanism of the green innovation effect of urban agglomerations from the perspective of the network and the mechanism of the effect of other economic and social factors on the network structure in the process of green innovation. In terms of research samples, most of the literature is limited to provincial or national data, with macro sample size and coverage of the survey area or relatively mature urban agglomerations area, which has certain geographical achievements that ignore the micro aspects. Compared with the previous literature, the main contributions of this article are as follows: First, the Great ChangshaZhuzhou-Xiangtan City Group is a micro-level region with vast space for innovation and progress regarding the economic development period, innovation period, and green environment construction period. In this regard, this article uses data from the Great Changsha-Zhuzhou-Xiangtan City Group from 2012 to 2018. The research selected eight prefecture-level cities in the Great Changsha-Zhuzhou-Xiangtan City Group specific to a certain degree of representativeness. Second, this article investigates the impact of network structure on green innovation using the unexpected output SBM model to measure the green innovation efficiency and the panel Tobit regression method of the re-centered influence function, which directly examines the marginal impact from the perspective of the network.

\section{Theoretical Mechanism Analysis}

3.1. Analysis of the Effect of Network Structure Characteristics on Green Innovation in Urban Agglomeration

The urban agglomeration network is the main form of urban spatial structure. For the development of urban agglomeration, the region is necessary to establish a network structure system. The network development of urban agglomeration is not only determined by internal attributes but also dominated by external dynamic factors. The dynamic mechanism of urban agglomeration network development focuses on green innovation. The key to researching networked green innovation rests within the high frequency of learning and communication between regional innovation subjects to promote the free flow of knowledge, technology, talents, and other innovation resources. By placing focus on the synergistic effect among innovation subjects in the urban agglomeration, this effect can improve the service of scientific and technological innovation and the level of achievement transformation to reduce the negative impacts on the environment and achieve green innovation. On the measurement of network characteristics for further characterization, domestic and foreign research mainly selects network scale, network openness, network structure hole, network density (network connection strength) [23]. Hence, the structural characteristics will be analyzed from four aspects: network scale, network openness, network structure hole, and network density. Its functions are as follows. 


\subsubsection{Network Scale}

Network scale in the network is the number of innovation subjects in urban agglomeration. The larger the number of creative subjects, the larger the network scale. The more substantial the heterogeneity between subjects, the richer the innovation resources. Heterogeneous network members have a high degree of complementary knowledge, which is conducive to reducing transaction costs and achieving results pertaining to the transformation of innovation.

\subsubsection{Network Openness}

Network openness is the capacity of network entities to absorb external information, related technologies, and other innovative resources. The higher the degree of openness, the stronger the ability to acquire external information, knowledge, technology, and other creative resources conducive to innovation.

\subsubsection{Network Structure Hole}

The more structural holes, the more social relations carry resources, providing opportunities for different innovation subjects to communicate and interact. The junction in the hub position occupies a structural hole and connects the creative subjects that lack direct contact to build a bridge of communication and cooperation, reduce information asymmetry effectively, and stimulate the realization of innovative achievements.

\subsubsection{Network Density}

Network density reflects the connection degree of innovation nodes. The closer is the connection between nodes in the network, the stronger the intention of innovation subjects to carry out innovation cooperation, and the more conducive to exchange and collaboration. High network density provides an effective platform for building and maintaining trust and cooperation among innovation subjects, conducive to obtaining external innovation resources within the innovation network, realizing the transformation of innovation achievements.

\subsection{Influencing Mechanism of Green Innovation in the Great Changsha-Zhuzhou-Xiangtan City Group Based on Network}

Regional knowledge production and technology transformation achieve development through innovation networks. Typically, innovation motivation stems from the connection between innovation subjects. Economic development provides a conducive environment for the flow of regional knowledge, technology, and other elements; government funding significantly contributes to the smooth running of innovative activities; improving the information infrastructure is a prerequisite for the flow of innovative talents among regions; the tertiary industry enables innovation subjects to have a competitive advantage, expanding the scale of innovation; urban education to promote regional innovation activities to carry out the study provides a platform for exchange. Hence, based on network structure characteristics, this paper arranges the influencing mechanisms of green innovation in the Great Changzhou-Zhuzhou-Xiangtan area, as shown in Figure 1.

\subsubsection{Economic Development Level}

Economic development is the strategic basis for building an innovative city and carrying out creative activities. Usually, the size of the regional economy and resources constrain innovation elements and innovation activities, and innovation communities are jointly built by innovation subjects and governments within the region, creating an implementable innovation network structure [24].

\subsubsection{Government Support}

The results of government support for innovation activities are affected by the intensity of investment. The reasons are as follows: First, the increase in government input 
stimulates enterprises and other innovation subjects to carry out scientific and technological innovation collaborations; second, the tendency of government investment, which crowds out private investment, leads to the crowding-out effect caused by the excessive accumulation of social capital. The government provides fiscal and tax subsidies for enterprises to build innovation network platforms. Enterprises in the innovation network rely on the support of the government to integrate innovation resources effectively and promote the development of innovative networks to enhance competitive advantages for regional innovation cooperation. Excessive capital tilt, which is not conducive to the transformation of research results, triggers inefficient capital utilization, inhibits the effect of large-scale innovation, imbalances the distribution of innovation elements, and hinders the flow of talents, knowledge, technology, and other elements in the innovation network.

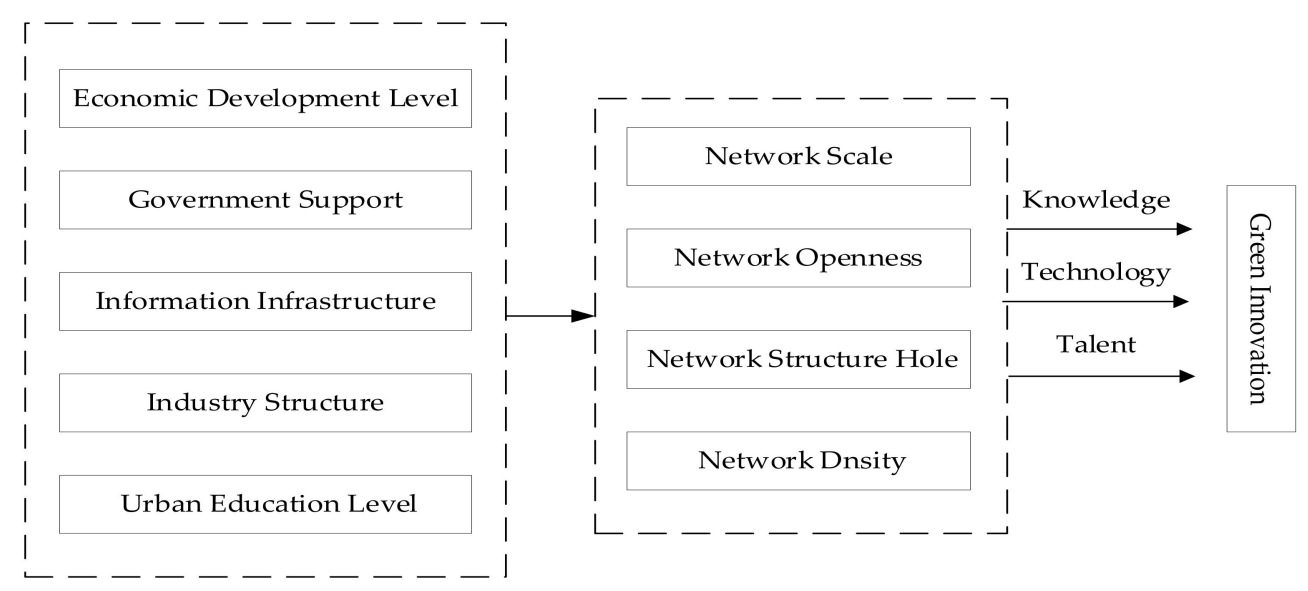

Figure 1. Influencing mechanisms of green innovation.

\subsubsection{Information Infrastructure}

Well-developed infrastructure is the primary condition for a region to attract innovative talent. A well-developed information network promotes knowledge flow and technology diffusion among innovation subjects. Moreover, convenient transportation and information networks provide essential conditions for expanding the scale of regional networks and enabling enterprises to engage in innovative activities.

\subsubsection{Industry Structure}

The industrial structure embedded in the innovation network is the reintegration and redistribution of resources. Innovative enterprises use innovation networks to enhance their competitiveness and optimize the structures of emerging industries. Based on undertaking traditional industries, urban agglomerations integrate into innovation networks, thus forming professional industrial layouts. The long-term, knowledge spillover in the innovation network leads to a nonlinear process from inferiority to continuous optimization of the industrial structure in innovation activities. Furthermore, with the improvement of resource utilization, innovation achievements are successfully transformed.

\subsubsection{Urban Education Level}

Urban education aims at cultivating high-quality and heterogeneous innovative talent. Importantly, only in the innovation network can heterogeneous talent realize resource complementarity and technology sharing, thus generating a synergistic effect among innovation subjects [25]. The embeddedness of network structure has an essential impact on innovation activities. Heterogeneous human capital, which is located in the hole of network structure, can obtain information resources by building relations with key innovation subjects and occupying information advantages. The more educated network members, the larger the network scale. Meanwhile, the more information resources embedded in the 
network, the more frequent communication and interaction conducive to constructing a complete network system.

\section{Model Methodology and Variable Selection}

\subsection{Research Methodology}

\subsubsection{SBM Model with Non-Expected Output}

Scholars mainly used the non-parametric DEA method in early studies on the measurement of green innovation efficiency. Since the traditional DEA model assumes that the output is the desired output, ignoring the influence of slack variables will significantly increase the measured efficiency values. At the same time, the indicators used in the experimental production process will produce lower efficiency. Therefore, the SBM model proposed by Tone [15] can effectively avoid the measurement bias caused by traditional DEA and measure the green innovation efficiency of the cities within the Great ChangshaZhuzhou-Xiangtan City Group. The following is the constructed evaluation model of green innovation efficiency.

$$
\begin{gathered}
\operatorname{Min} \rho=\frac{1-\frac{1}{m} \sum_{i=1}^{m} \frac{s_{i}^{-}}{x_{i k}}}{1-\frac{1}{q_{1}+q_{2}}\left(\sum_{r=r k}^{q_{1}} \frac{s_{r}^{+}}{y_{r k}}+\sum_{t=1}^{q_{2}} \frac{s_{t}^{-}}{z_{r k}}\right)} \\
\text { s.t. }\left\{\begin{array}{c}
\sum_{j=1}^{n} x_{i j} \lambda_{j}-s_{i}^{-} \leq x_{i k} \\
j \neq k \\
\sum_{j=1}^{n} y_{i j} \lambda_{j}-s_{i}^{+} \leq y_{i k} \\
j \neq k \\
\sum_{j=1}^{n} z_{i j} \lambda_{j}-s_{i}^{z^{-}} \leq z_{r k} \\
j \neq k \\
\lambda, s^{-}, s^{+} \geq 0
\end{array}\right.
\end{gathered}
$$

In the formula, there are $n$ decision units (DUM), which include the input, expected output, and unexpected output. The number of types is represented by $m, q_{1}, q_{2}$, respectively. The slack variables of input, expected output, and unexpected output are represented by $s^{-}, s^{+}, s^{z^{-}}$, respectively. In general, $\lambda$ is the weight of the decision unit and $\rho$ is the efficiency value of DMU. As known, the value range is between 0 and 1 . Therefore, effective DUM is obtained through the SBM model of unexpected output.

\subsubsection{Panel Tobit Model}

The Tobit regression model, also known as a truncated model, was proposed by Tobit. The limited Tobit regression model can avoid the deviation of ordinary least square estimation results. The Tobit regression model is used to ensure unbiased and valid estimation results. After the measurement of green innovation efficiency is completed, the value range of GIE is between 0 and 1 , and the basic model is as follows:

$$
\left\{\begin{array}{l}
Y_{\mathrm{it}}^{*}=\alpha_{0}+X_{i t} \beta+\varepsilon_{i} \\
Y_{i t}=Y_{\mathrm{it}}^{*} \text { if } 1 \geq Y_{\mathrm{it}}^{*} \geq 0 \\
Y_{i t}=0 \text { if } Y_{\mathrm{it}}^{*} \leq 0 \\
Y_{i t}=1 \text { if } Y_{\mathrm{it}}^{*} \geq 1
\end{array}\right.
$$

In the formula, $Y_{i t}^{*}$ the explanatory variable vector, $Y_{i}$ is the value of the observed dependent variable, $\beta$ is the regression parameter vector, and $\varepsilon_{i}$ represents the stochastic 
perturbation term. The panel Tobit regression model constructed based on influencing factors is as follows.

$$
G I E=\alpha_{0}+\beta_{1} \ln G D P_{i t}+\beta_{2} \ln G O V_{i t}+\beta_{3} \ln I N F_{i t}+\beta_{4} \ln I N S_{i t}+\beta_{5} \ln E D U_{i t}+\varepsilon_{i t}
$$

\subsection{Variables and Data}

4.2.1. Variable Selection

Input Variables

Green innovation efficiency is a complex system with multiple inputs and outputs. The Great Changsha-Zhuzhou-Xiangtan City Group constitutes a networked innovation system. Selecting corresponding indicators is based on green innovation input and green innovation output to estimate the green innovation efficiency of eight cities in the Great Changsha-Zhuzhou-Xiangtan City Group. According to the status quo of green innovation in the Great Changsha-Zhuzhou-Xiangtan City Group and the data availability, we constructed the evaluation index system of green innovation efficiency. The measurement of green innovation efficiency of cities in the Great Changsha-Zhuzhou-Xiangtan City Group should reflect the theme "Green" and the network effect of urban agglomeration innovation. Therefore, this paper integrates the green concept into the input-output factors and comprehensively considers the environmental pollution situation. Based on the network characteristics of urban agglomeration, the input indexes mainly include: First, using the number of universities, research institutions, and enterprises to represent network scale; second, network openness measures the ability of urban agglomeration to absorb external knowledge and information by foreign direct investment; third, the network structure hole selects the technology market transaction amount as the bridge of knowledge flow and technical cooperation among innovation subjects in the innovation network; fourth, the network density is represented by the external expenditure of Research and Development (R\&D) expenditure in universities [23].

\section{Output Variables}

Output can be divided into expected output and unexpected output. Expected outputs mainly include patent applications and per capita GDP. Patent data can reflect the results of urban innovation output comprehensively; therefore, the number of patent applications is selected to represent. Per capita GDP demonstrates the level of regional economic growth. Generally, as unexpected outputs, the comprehensive environmental index is used to represent the environmental benefit output of the undesired output, and the environmental pollution comprehensive index is calculated by the entropy weight method of the three industrial wastes, which are the industrial wastewater discharge, the industrial sulfur dioxide discharge, and the industrial smoke emission respect, respectively. Specific indicators are shown in Table 1 below.

Table 1. Evaluation index system of green innovation efficiency.

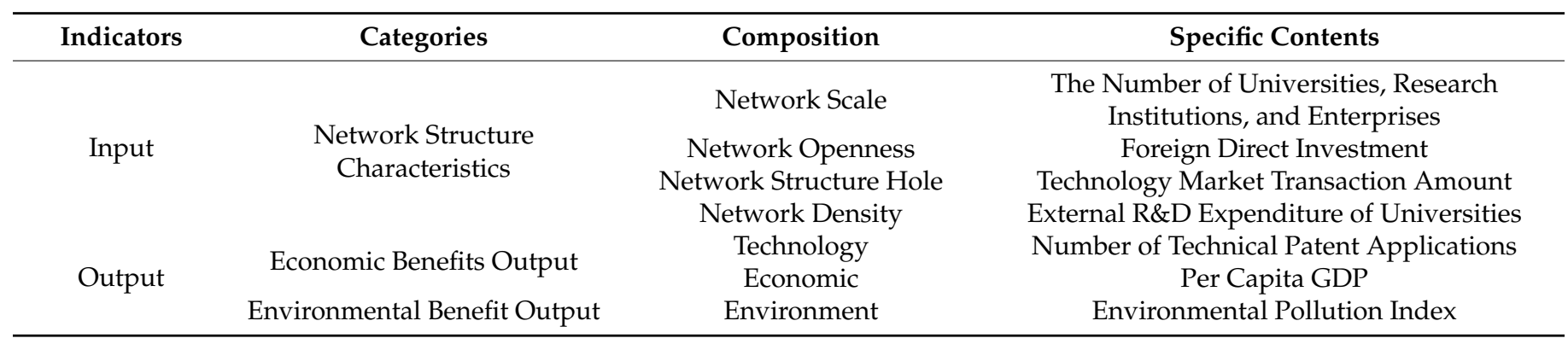

Theoretically, in urban innovation activities, any factors related to innovation activities will impact innovation efficiency. According to the current situation of urban green development, economic development requires a high level of technical innovation. On the contrary, the economic development level is also bound to increase innovation input, 
forming a positive feedback effect. Therefore, the influencing factors of green innovation efficiency should include the level of economic development (GDP), which is represented by per capita GDP. Since communication infrastructure plays the most important role in innovation among the four infrastructures of the highway, railway, communication, and energy, it is expressed as the proportion of regional postal and telecommunication services in GDP (INF) [26]. Government support (GOV) is represented by the proportion of regional science and technology financial expenditure in local financial expenditure. Industrial structure (INS) uses the proportion of the added value of the tertiary industry in the gross regional product, which reflects the ratio of the tertiary industry in the national economy to measure. Urban education can provide high-quality human capital for innovation and become a significant factor influencing the regional innovation system. Therefore, this study selected urban education level $(E D U)$ as the influencing factor and represented by the number of university students [27] (see Table 2 for details).

Table 2. Influencing factors and variables of green innovation efficiency.

\begin{tabular}{|c|c|c|}
\hline Influencing Factors & Variable Abbreviation & Variable Definition \\
\hline Economic Development Level & GDP & Per Capita GDP \\
\hline Government Support & GOV & $\begin{array}{c}\text { Regional Science and Technology Expenditure Accounted for the } \\
\text { Proportion of Local Fiscal Expenditure }\end{array}$ \\
\hline Information Infrastructure & INF & $\begin{array}{l}\text { Regional Posts and Telecommunications Accounted for the } \\
\text { Proportion of GDP }\end{array}$ \\
\hline Industry Structure & INS & $\begin{array}{c}\text { The Proportion of The Added Value of } \\
\text { The Tertiary Industry in GDP }\end{array}$ \\
\hline Urban Education Level & EDU & University Students \\
\hline
\end{tabular}

\subsection{Data Sources}

We included eight prefecture-level cities in the Great Changsha-Zhuzhou-Xiangtan City Group from 2012 to 2018 as the research objects, namely, Changsha, Zhuzhou, Xiangtan, Hengyang, Yueyang, Changde, Yiyang, and Loudi. The original data of the indicators in this paper came predominantly from the statistical bulletins of the corresponding prefecture-level cities in Hunan Statistical Yearbook, Hunan Science and Technology Statistical Yearbook, and China Urban Statistical Yearbook (2012-2018). Some missing values are complemented by linear interpolation.

\section{Measurement and Characteristics of Green Innovation Efficiency of Great Changsha-Zhuzhou-Xiangtan City Group Based on Network}

5.1. Measurement Results of Green Innovation Efficiency of the Great Changsha-Zhuzhou-Xiangtan City Group Based on Network

Using the constructed SBM model of unexpected output to calculate the green innovation efficiency of cities in the Great Changsha-Zhuzhou-Xiangtan City Group from 2012 to 2018, the results are shown in Table 3. Meanwhile, cloud model and system cluster analysis were used to analyze the normal distribution and segmentation of green innovation efficiency in the Great Changsha-Zhuzhou-Xiangtan City Group. The results are shown in Figures 2 and 3, respectively.

Table 3. Green innovation efficiency of urban agglomeration.

\begin{tabular}{cccccccccc}
\hline Region & $\mathbf{2 0 1 2}$ & $\mathbf{2 0 1 3}$ & $\mathbf{2 0 1 4}$ & $\mathbf{2 0 1 5}$ & $\mathbf{2 0 1 6}$ & $\mathbf{2 0 1 7}$ & $\mathbf{2 0 1 8}$ & Mean & Ranking \\
\hline Changsha & 0.8153 & 1 & 1 & 1 & 1 & 1 & 0.8325 & 0.9497 \\
Zhuzhou & 1 & 0.7121 & 0.7709 & 0.8196 & 0.7895 & 0.9407 & 1 & 0.8864 & 1 \\
Xiangtan & 0.6488 & 0.6891 & 0.6624 & 0.7185 & 0.7687 & 0.7898 & 0.7953 & 0.7247 \\
Hengyang & 0.2335 & 0.4882 & 1 & 0.597 & 0.8911 & 1 & 0.5197 & 0.6756 & 5 \\
Yueyang & 1 & 1 & 1 & 1 & 1 & 0.5614 & 1 & 0.9373 \\
Changde & 0.4312 & 0.7856 & 0.8108 & 0.5851 & 0.6938 & 0.6854 & 0.6589 & 0.6644 & 2 \\
Yiyang & 0.4948 & 0.4064 & 0.3032 & 0.6408 & 1 & 0.4474 & 1 & 0.6132 & 8 \\
Loudi & 1 & 0.6047 & 1 & 1 & 1 & 1 & 0.3769 & 0.8545 \\
Mean & 0.7030 & 0.7108 & 0.8184 & 0.7951 & 0.8929 & 0.8031 & 0.7729 & & 4 \\
\hline
\end{tabular}




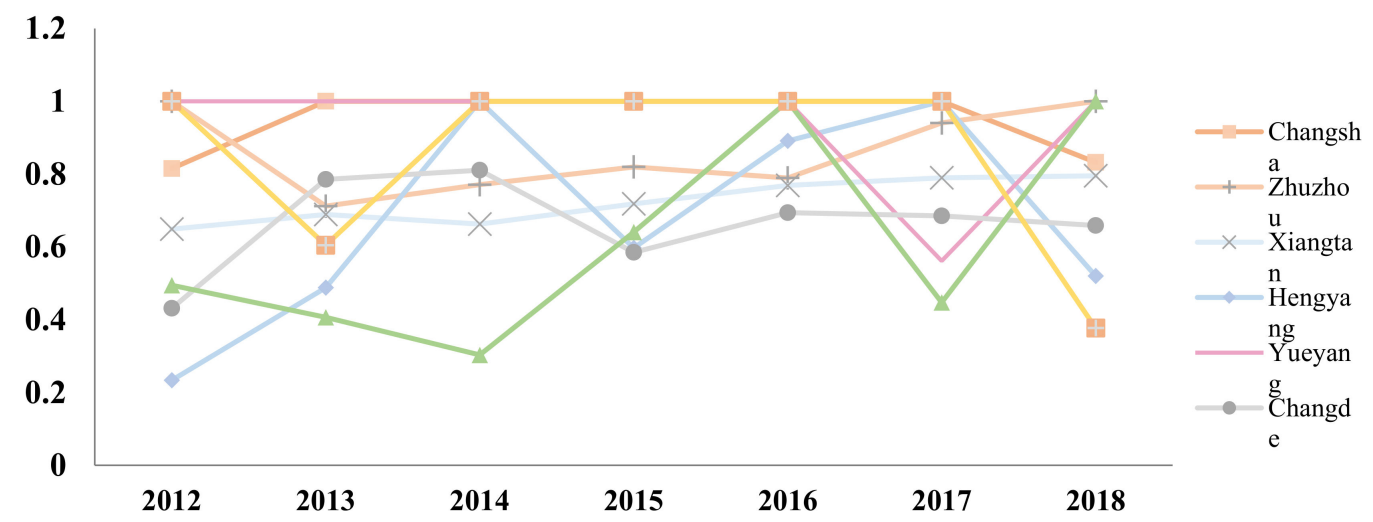

Figure 2. Distribution trend map of green innovation efficiency in the urban agglomeration.

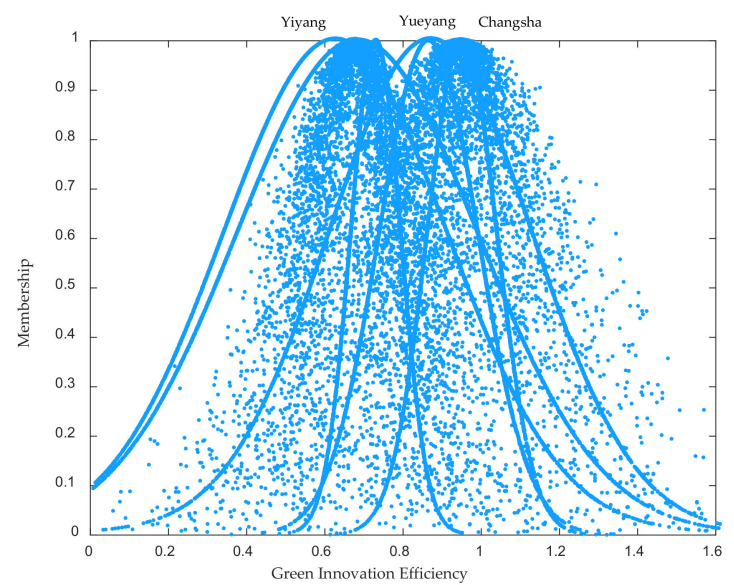

Figure 3. Normal cloud-membership degree distribution of green innovation efficiency in the Great Changsha-Zhuzhou-Xiangtan City Group.

\subsection{Characteristics Analysis of Green Innovation Efficiency of the Great Changsha-Zhuzhou-Xiangtan City Group Based on Network}

The green innovation efficiency of the Great Changsha-Zhuzhou-Xiangtan City Group was generally stable. In terms of the overall time series, the mean green innovation efficiency values of the Great Changsha-Zhuzhou-Xiangtan City Group from 2012 to 2018 were $0.7030,0.7108,0.8184,0.7951,0.8929,0.8031$, and 0.7729 , respectively. The overall mean values of green innovation efficiency fluctuated at a medium level and showed a stable trend. This may be because Hunan province has focused on constructing a two-oriented society in the core area of urban agglomeration, improving the overall green development of the Great Changsha-Zhuzhou-Xiangtan City Group to a certain extent in recent years. At the same time, influenced by the international environment, China's economy has slowed down; with tremendous downward pressure, the transformation of technological innovation achievements into practical productivity in the Great Changsha-ZhuzhouXiangtan City Group is insufficient. In the meantime, rational allocation and utilization of innovative resources are hindered, so the overall efficiency is low. The distribution trend of green efficiency in urban agglomeration is shown in Figure 2. Therefore, the green innovation development of urban agglomeration cannot be achieved without a favorable innovation environment.

The green innovation efficiency of the Great Changsha-Zhuzhou-Xiangtan City Group presents the characteristics of "urban gradient" development. As shown in Figure 3, Changsha and Yueyang rank high in green innovation efficiency and have a maximum advantage for green innovation development. On the one hand, Changsha has an extensive network 
scale and high network openness. As a provincial capital city, Changsha is inextricably linked to its position in the network structure hole in the innovation system. As a network structure hole for strengthening regional cooperation, Yueyang is the "main battlefield" of Hunan's growth pole construction and an essential fulcrum for docking the Yangtze River Economic Belt construction. Other cities in the urban agglomeration-Zhuzhou and Xiangtan - have dominant industries concentrated in secondary industries, such as iron and steel industries. Therefore, extensive development may cause environmental pollution; their green innovation efficiency, therefore, is slightly behind Changsha. Yiyang has continuously lagged with its green innovation efficiency, which has restricted the balanced development of green innovation in the Great Changsha-Zhuzhou-Xiangtan City Group. According to the echo theory, the development of green innovation is limited by its economic scale, resulting in a lack of endogenous motivation and issues with green development [28]. Therefore, we can conclude that it can be divided into three gradients: (1) Changsha and Yueyang, (2) Yiyang, and (3) other cities.

The "mid-stream drive" difference of green innovation efficiency in the Great Changsha-Zhuzhou-Xiangtan City Group is noticeable. Figure 3 shows the apparent differences between cities such as Changsha and Yiyang and other cities in the urban agglomeration; however, other cities need further analysis based on Figures 4 and 5 . We can see from Figure 4 that Xiangtan, Changde, and Hengyang are classified into one category, and the green innovation efficiency value is between 0.6 and 0.7. Combined with Figure 5, Xiangtan moves up by one place, Changde moves up by one place, and Hengyang moves up by two. The reasons are as follows. First, Xiangtan encourages independent innovation and strengthens R\&D and project promotion by the government bonus policy. For example, the Implementation Measures for Encouraging Scientific and Technological Innovation in Xiangtan High-tech Zone, issued in 2016, enhanced the guiding role of government expenditure on green innovation and promoted the innovation efficiency of the region to maintain an excellent level. The Changde Office of Science and Technology issued some awards in Changde Science and Technology Awards in 2017 to stimulate the initiative of innovation subjects, accelerate the transformation of innovation achievements, and improve the innovation system. Hengyang proposed Measures for The Administration of Subsidies for Science and Technology Services (trial) for innovative services subsidies, enhancing the innovation capacity of relevant enterprises. Second, Zhuzhou and Loudi are the second types, with a green innovation efficiency ranging from 0.85 to 0.90 . Zhuzhou moves up by one place, while Loudi moves down by four places. The reason may be that the limited economic scale is the main factor in developing green innovation. The small scale of a regional innovation network and insufficient innovation investment seriously hinder the improvement of innovation efficiency.

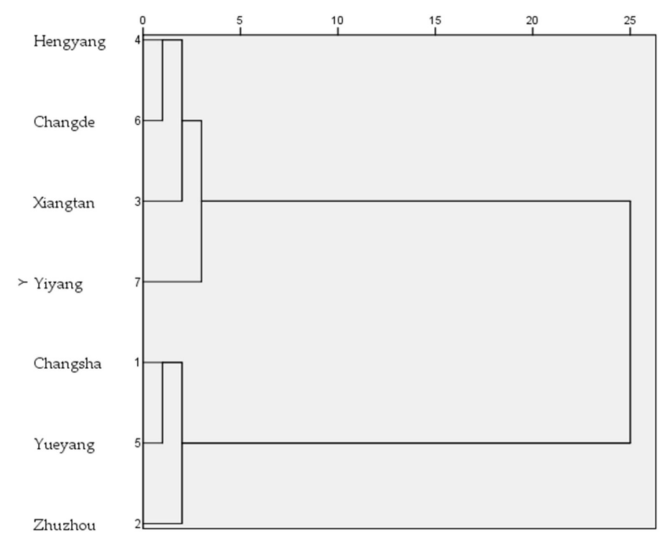

Figure 4. Cluster tree of green innovation efficiency in the Great Changsha-Zhuzhou-Xiangtan City Group. 


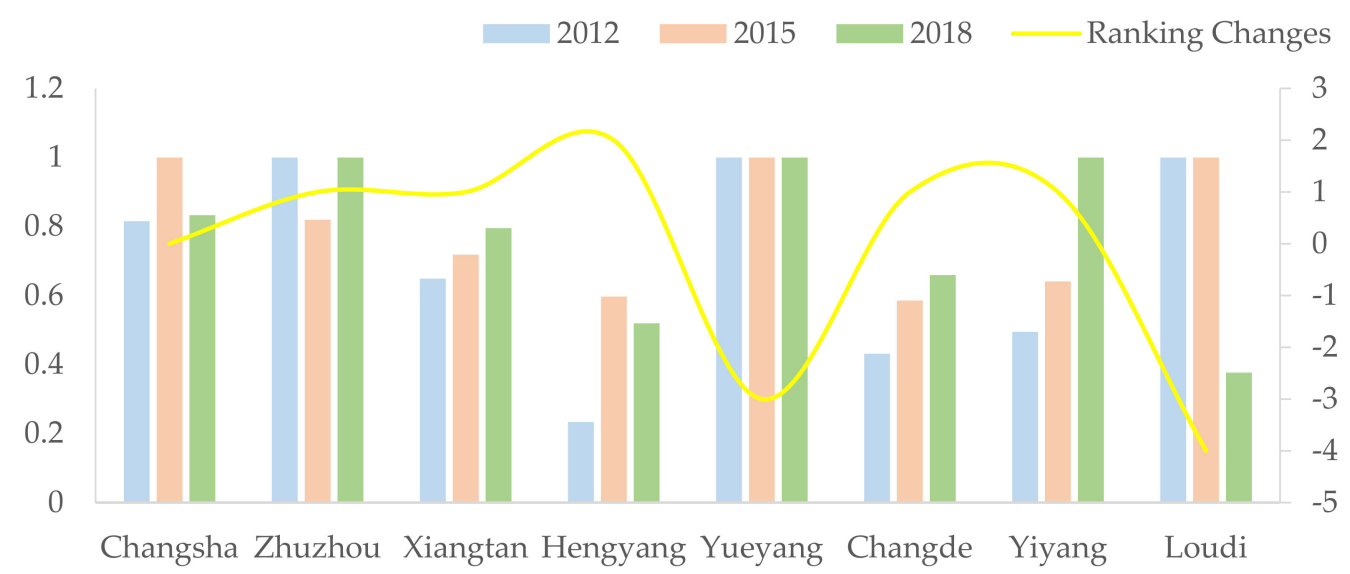

Figure 5. Trend of green innovation efficiency in the Great Changsha-Zhuzhou-Xiangtan City Group.

\section{Research on The Influencing Factors of Green Innovation in the Great Changsha-Zhuzhou-Xiangtan City Group Based on Network}

Based on the theoretical mechanism of the network and the green innovation efficiency measured by the unexpected output SBM model, the empirical analysis of influencing factors is conducted. Unit root tests were carried out prior to regression result analysis to ensure the rigor and correctness of regression results.

\subsection{Unit Root Test}

Combined with the SBM model of unexpected output, this paper calculates the green innovation efficiency data of the Great Changsha-Zhuzhou-Xiangtan City Group from 2012 to 2018. It conducts regression analysis with green innovation efficiency as the dependent variable. Firstly, the unit root test of panel data is carried out to enable a more rigorous and reliable empirical process and avoid the pseudo-regression caused by the non-stationary variables to ensure the effectiveness of the estimation results. The stationary unit root test mainly uses LLC, IPS, ADF-Fisher, and PP-Fisher methods to test the variables. The formula of the unit root test is as follows:

$$
\chi_{i t}=\rho_{i} \chi_{i, t-1}+\varepsilon_{i t}
$$

The unit root test can be divided into two categories: one category is the LLC test, which is the same regression coefficient. Additionally, it changes according to different cross-sections, namely, IPS test, ADF-Fisher test and PP-Fisher test. The first test results show that the sequence of a variable is unstable, so take the logarithm to carry on the stability test. As shown in Table 4, the results obtain the overall rejection of the original hypothesis of 'existence of unit root', and then carry out the panel Tobit random effect regression; the results are shown in Table 5.

\subsection{Analysis of Regression Results of Influencing Factors}

According to the regression results, the relevant influencing factors are as follows:

First: the economic development level. The economic development level regression results show a significantly positive impact on green innovation efficiency, and the impact coefficient is 0.9745 . The level of regional economic development promotes the improvement of green innovation efficiency. A higher GDP encourages individuals to pursue green and low-carbon products and facilitates the optimal allocation of green innovation resources [29]. Moreover, it effectively avoids the redundancy of network scale, enables the effectiveness of the network structure as a whole, and improves the conversion rate of innovation achievements. 
Table 4. Unit root test results.

\begin{tabular}{|c|c|c|c|c|}
\hline \multirow{2}{*}{ Variable } & \multicolumn{4}{|c|}{ Unite Root Tests } \\
\hline & LLC Test & IPS Test & Fisher-ADF Test & Fisher-PP Test \\
\hline \multirow{2}{*}{ GDP } & $-4.4708^{* * *}$ & 1.1959 & $32.4882 * * *$ & $25.7640^{* *}$ \\
\hline & $(0.0000)$ & $(08841)$ & $(0.0086)$ & $(0.0574)$ \\
\hline \multirow{2}{*}{ INF } & $-6.5998^{* * *}$ & -0.6477 & 17.3999 & 8.7567 \\
\hline & $(0.0000)$ & $(0.2586)$ & $(0.3602)$ & $(0.9231)$ \\
\hline \multirow{2}{*}{ GOV } & $-3.9148^{* * *}$ & 2.1166 & $225.9521^{* * *}$ & 6.9460 \\
\hline & $(0.0000)$ & $(0.9829)$ & $(0.0000)$ & $(0.9743)$ \\
\hline \multirow{2}{*}{ INS } & -1.1409 & $(0.8945)$ & 0.3698 & 1.1016 \\
\hline & $(0.0574)$ & $(0.1269)$ & $(1.0000)$ & $(1.0000)$ \\
\hline \multirow{2}{*}{ EDU } & $-25.6417^{* * *}$ & 0.2159 & 0.8512 & 0.3842 \\
\hline & $(0.0000)$ & $(0.5855)$ & $(1.00000$ & $(1.0000)$ \\
\hline \multirow{2}{*}{$\operatorname{lnGDP}$} & $-1.7013^{* * *}$ & 0.5643 & $85.0089^{* * *}$ & $105.4833^{* * *}$ \\
\hline & $(0.0444)$ & $(0.7137)$ & $(0.0000)$ & $(0.0000)$ \\
\hline \multirow{2}{*}{$\operatorname{lnINF}$} & $-4.0939^{* * *}$ & 0.5711 & $176.0313^{* * *}$ & $27.6454^{* * *}$ \\
\hline & $(0.0000)$ & 0.7160 & $(0.0000)$ & $(0.0348)$ \\
\hline \multirow{2}{*}{$\operatorname{lnGOV}$} & $-7.2467^{* * *}$ & -1.1113 & $155.8811^{* * *}$ & 7.5889 \\
\hline & $(0.0000)$ & $(0.1332)$ & $(0.0000)$ & $(0.9602)$ \\
\hline \multirow{2}{*}{$\operatorname{lnINS}$} & $-16.3869^{* * *}$ & 0.7972 & 0.6236 & 3.5595 \\
\hline & $(0.0000)$ & $(0.7873)$ & $(1.0000)$ & (0.9995) \\
\hline \multirow{2}{*}{$\operatorname{lnEDU}$} & $-6.2933^{* * *}$ & -0.3458 & 1.9785 & 1.119 \\
\hline & $(0.0000)$ & $(0.3647)$ & $(1.0000)$ & $(1.0000)$ \\
\hline
\end{tabular}

Table 5. Regression results of influencing factors of green innovation in the Great Changsha-ZhuzhouXiangtan City Group based on network.

\begin{tabular}{ccccc}
\hline \multirow{2}{*}{ Variable } & Coefficient & \multicolumn{2}{c}{ Panel Tobit Random Effect Model } & \\
& Standard Error & Z Value & $p$-Value \\
\hline lnGDP & $0.9745^{* * *}$ & 0.213 & 4.57 & 0.000 \\
$\operatorname{lnGOV}$ & 0.0147 & 0.061 & 0.24 & 0.809 \\
lnINF & 0.0083 & 0.085 & 0.10 & 0.922 \\
lnINS & $-0.6619^{* * *}$ & 0.189 & -3.51 & 0.000 \\
lnEDU & $-0.1358^{* * *}$ & 0.055 & -2.48 & 0.013 \\
Constant & $-0.9210^{* * *}$ & 2.310 & -4.01 & 0.000 \\
Wald chi2(5) & & & 31.08 & \\
\hline
\end{tabular}

Note: ${ }^{* * *}$ represents significance at the $1 \%$ level.

Second: government support. The regression results show that the efficiency of green innovation has a negative impact and is not statistically significant. The reasons are as follows. First, in government support for green innovation investment, excessive government involvement has caused innovation resource wastage. Second, excessive government expenditure leads to the crowding-out effect in the innovation activities of enterprises and scientific research institutions. Therefore, the government should invest a reasonable range of fiscal expenditure and rationalize innovation resources.

Third: the level of information infrastructure. Regression results show that the efficiency of green innovation has a positive impact, but not through the significance test. Results show that the current level of information infrastructure of the Great ChangshaZhuzhou-Xiangtan City Group shows an Internet trend, which has a 'crowding out effect' on postal and telecommunication services. The Internet is introduced into the innovation network as a carrier to enable the innovation synergy relationship informatization and reduce information transaction costs. Therefore, the level of networked information infrastructure has higher innovation efficiency. This conclusion is similar to the research in Zhongchao Wu [23].

Fourth: industrial structure. The empirical results show that industrial institutions have a negative impact on green innovation and pass the significance test. Possible reasons are as follows: first, in the process of embedding the tertiary industry into the innovation 
network, enterprises and other innovation subjects fail to make full use of innovation resources, impeding the process of knowledge spillover; the competitive advantage is not apparent, leading to the failure of the tertiary industry to significantly promote the improvement of green innovation efficiency [30]. Second, the depth and breadth of network openness are inadequate, which is not conducive to the flow and reorganization of industrial elements. Therefore, penetrating the barriers of the closed innovation system, building a high-level open innovation platform, and optimizing resource allocation are the keys to the development of green innovation.

Fifth: the urban education level. The regression results of the urban education level show that it negatively influences green innovation efficiency, and the influence coefficient is 0.1358 . This indicates that the current education level has no significant promoting effect on improving green innovation efficiency in the Changsha-Zhuzhou-Xiangtan City Group. Possible reasons are as follows: school education fails to achieve innovation-driven teaching, and innovative education resources in universities fail to achieve innovation integration with scientific research institutions and related enterprises. Moreover, low-efficiency allocation of innovation resources leads to redundancy of network scale; heterogeneous human capital located in the hole of network structure cannot obtain relevant information resources through connecting innovation subjects. Therefore, there is no significant improvement in innovation efficiency, similar to the research result of Yuwen Peng [31].

\section{Conclusions and Recommendations}

Urban agglomeration can be regarded as a network innovation system with 'inputoutput.' Based on a heterogeneous network perspective, this paper constructs an unexpected SBM model including R\&D investment and analyzes the green innovation efficiency of eight cities in the Great Changsha-Zhuzhou-Xiangtan City Group from 2012 to 2018. On this basis, the panel Tobit model is used to analyze the influencing factors of green innovation efficiency to provide feasible suggestions for accelerating the innovation development of the Great Changsha-Zhuzhou-Xiangtan City Group and realizing energy conservation and emission reduction. The following conclusions are drawn:

First, the overall mean value of green innovation efficiency in the Great ChangshaZhuzhou-Xiangtan City Group fluctuates between 0.70 and 0.85 . The overall efficiency value is at the medium level, showing a stable trend. The green innovation efficiency has particular room for improvement. Specifically for cities, the distribution of urban green innovation efficiency within the region has the characteristics of gradient development and mid-stream drive apparent differences.

Second, in the process of networked innovation, economic development to promote the overall effectiveness of the network structure has a positive influence on green innovation. The low efficiency of urban educational resources utilization and the weak advantage of industrial structure renders the depth and breadth of network openness unsuitable for the development of green innovation; the level of government support and infrastructure has no significant effect on it.

Based on the empirical analysis, this paper proposes the following recommendations:

First, the high-quality development of Hunan province must promote regional collaborative innovation and green development. Hunan province should implement the strategy of "Three High and Four New", giving full play to the radiation role of the core area of the Great Changsha-Zhuzhou-Xiangtan City Group and linking the cities surrounding the Great Changsha-Zhuzhou-Xiangtan City Group. The cities Changsha and Yueyang, with improved green development, should set an example for the radiation range of green innovation. We are encouraging enterprises to independently innovate and play leading roles as enterprises, universities, and research institutions in innovation and create an open and efficient platform for the transformation of innovation achievements. Zhuzhou, Xiangtan, Hengyang, and Changde cities should continuously maintain their advantage of being efficient cities-overcoming regional boundaries to achieve regional cooperation. For cities with a small economic scale, such as Loudi, we should strengthen regional coop- 
eration development, draw lessons from the experience of efficient city development, build an innovation cooperation center system, increase the scale of network construction, and gradually realize the transformation of innovation achievements. For cities with insufficient green innovation and development capacity in Yiyang, we should actively learn from the green development experience of Changsha, improve the construction of collaborative mechanisms for urban green innovation, and encourage technological innovation to benefit innovative development.

Second, it is essential to form an innovation network system with enterprises at its core, including higher-education institutions, research institutions, and other innovation subjects; expand the scale of the innovation network, strengthen the innovation links between subjects, further enhance the enthusiasm and initiative of independent innovation, and effectively improve the efficiency of green innovation.

Third, economic development mainly depends on technological innovation, accelerating technological innovation research and development. The transformation of the economic development model is essential in order to save resources, protect the environment, focus efforts on green innovation efficiency, actively learn from the developed areas of green innovation development, optimal green innovation resources allocation, and enhance the efficiency of green innovation.

Fourth, it is vital to vigorously improve the construction of education service systems and invest reasonably in education resources. We will foster outstanding innovative talent, guide creative and talented university graduates to form enterprises and realize the diffusion of technological knowledge. The purpose is to ensure the rational utilization of regional innovation resources, promote the upgrading of industrial institutions, and realize the development of green innovation.

Author Contributions: Conceptualization, L.W. and L.C.; methodology, L.W. and L.C.; software, L.W. and L.C.; formal analysis, L.W. and L.C.; resources, L.W. and L.C.; data curation, L.W. and L.C.; writing — original draft preparation, L.W.; writing—review and editing, L.W. and L.C.; supervision, L.W., W.Y. and L.C.; project administration, W.Y. and L.C.; funding acquisition, W.Y. All authors have read and agreed to the published version of the manuscript.

Funding: This work was funded by The National Social Science Fund of China (grant number 20BGL299).

Data Availability Statement: We are taking eight prefecture-level cities in the Great ChangshaZhuzhou-Xiangtan City Group from 2012 to 2018 as the research objects, including Changsha, Zhuzhou, Xiangtan, Hengyang, Yueyang, Changde, Yiyang, and Loudi. The original data of the indicators in this paper mainly come from the statistical bulletins of the corresponding prefecturelevel cities in Hunan Statistical Yearbook, Hunan Science and Technology Statistical Yearbook, and China Urban Statistical Yearbook (2012-2018).

Acknowledgments: We would like to express our gratitude to all those who helped us during the writing of this article. Our deepest gratitude goes first and foremost to Yaping $\mathrm{Hu}$, who are from the Hunan University of Science and Technology in China, for their constant encouragement and guidance.

Conflicts of Interest: The authors declare no conflict of interest.

\section{References}

1. Xu, Y.Q.; Zeng, G.; Wang, Q.Y. The evolution and optimization strategy of collaborative innovation network pattern in Yangtze River Delta urban agglomerations. Econ. Geogr. 2018, 38, 133-140.

2. Huallacháin, B.ó.; Lee, D.-S. Urban centers and networks of co-invention in American biotechnology. Ann. Reg. Sci. 2014, 52, 799-823. [CrossRef]

3. Lee, D.-S. Towards Urban Resilience through Inter-City Networks of Co-Invention: A Case Study of U.S. Cities. Sustainability 2018, 10, 289. [CrossRef]

4. Sheng, Y.W.; Gou, Q.; Song, J.P. Research on network structure and innovation efficiency of urban agglomeration: A case study of Beijing-Tianjin-Hebei, Yangtze River Delta and Pearl River Delta. Geogr. Sci. 2020, 40, 1831-1839.

5. Ren, S.G.; Hu, C.Y.; Wang, L.W. An empirical study on the impact of network structure on regional innovation capability in China. Syst. Eng. 2011, 29, 50-55. 
6. $\mathrm{Wu}, \mathrm{Z} . \mathrm{C}$. Research on regional innovation performance based on stochastic frontier: From the perspective of innovation network Structure. Technol. Econ. 2020, 39, 120-131.

7. Li, X.Y. Regional science and technology innovation research based on network. Sci. Manag. Res. 2014, 32, 52-55.

8. Liu, J.T. The Canonical Correlation Analysis of innovation Network Structure Characteristics to innovation output. Stat. Decis. 2019, 35, 118-120.

9. Rennings, K. Redefining innovation-Eco-innovation research and the contribution from ecological economics. Ecol. Econ. 2000, 32, 319-332. [CrossRef]

10. Driessen, P.H.; Hillebrand, B.; Kok, R.; Verhallen, T.M.M. Green New Product Development: The Pivotal Role of Product Greenness. IEEE Trans. Eng. Manag. 2013, 60, 315-326. [CrossRef]

11. Kemp, R. Eco-innovation: Definition, Measurement and Open Research Issues. Econ. Politica 2010, 60, 397-420.

12. Li, D.; Zeng, T. Are China's s intensive pollution industries greening? An analysis based on green innovation. J. Clean. Prod. 2020, 259, 120901. [CrossRef]

13. Zeng, J.; Skare, M.; Lafont, J. The co-integration identification of green innovation efficiency in the Yangtze River Delta region. Eur. J. Oper. Res. 2021, 134, 252-262. [CrossRef]

14. Qian, L.; Wang, W.; Xiao, R. Research on the regional disparities of China's industrial enterprises green innovation efficiency from the perspective of shared inputs. China Population. Resour. Environ. 2016, 26, 149-157.

15. Tone, K. A slacks-based measure of efficiency in data envelopment analysis. Eur. J. Oper. Res. 2001, 03, 498-509. [CrossRef]

16. Ten, T.W.; Qu, C.Y.; Hu, S.L.; Zeng, G. Green innovation efficiency pattern differentiation and spatial correlation characteristics of Urban agglomeration in Yangtze River Delta. J. E. China Norm. Univ. 2019, 5, 107-117.

17. Zhang, W.; Li, H.L.; An, X.B. Discussion on the Theoretical Model and Thinking of Enhancing China's Green Innovation Ability by using FDI. Manag. World 2011, 12, 170-171.

18. Li, J.; Du, Y. Can Spatial effect of Environmental Regulation on Green Innovation Efficiency-Evidence from Prefectural-level Cities in China. J. Clean. Prod. 2020, 286, 125032. [CrossRef]

19. Zhou, M.; Wu, C.Q. The impact of government subsidies on some technological innovations. Sci. Res. Manag. 2017, 38, 574-580.

20. Yang, L.G. Evaluation of ecosystem security in urban agglomeration based on ecological footprint: A case study of ChangshaZhuzhou-Xiangtan Urban agglomeration. Study World Geogr. 2009, 18, 74-82.

21. Gu, Z.L.; Ma, T.; Yuan, X.H.; Zhang, X.M.; Wang, X. Ecological protection and development of greenheart in Changsha-ZhuzhouXiangtan Urban agglomeration. Resour. Environ. Yangtze Basin 2010, 19, 1124-1131.

22. Li, W.B.; Li, C. Can "Two-oriented Society" Comprehensive Reform Zone promote green Development? J. Financ. Econ. 2018, 44, 24-37.

23. Wu, Z.C. Network structure, innovation infrastructure and regional innovation performance: An analysis based on network DEA multiplication Model. J. Beijing Jiaotong Univ. 2021, 20, 79-89.

24. Lin, F. Co-construction, Co-governance and Shared benefits: Regional integration from the perspective of innovative economy: A case study of Yangtze River Delta integration development. West. BBS 2020, 30, 68-77.

25. Li, Y.Z.; Yang, J.N.; Tian, X.F. Research on the relationship between incubation network embedment, entrepreneurial efficacy and entrepreneurial performance. Sci. Sci. Sci. Technol. Manag. 2016, 37, 169-180.

26. Lv, Y.W.; Xie, Y.X.; Lou, X. Research on spatial-temporal transition and convergence trend of regional green innovation efficiency in China. J. Res. Quant. Tech. Econ. 2020, 37, 78-97.

27. Li, J.Y.; Li, C.; Li, Z.Y. Urban green innovation efficiency evaluation and Its Influencing Factors analysis. Stat. Decis. 2017, 20, 116-120.

28. Dong, H.Z.; Li, X.; Zhang, R.J. Spatial and temporal characteristics and driving factors of green innovation efficiency in Guangdong-Hong Kong-Macao Greater Bay Area. Econ. Geogr. 2021, 41, 134-144.

29. Li, J.; Ma, X.F. Spatial and temporal differences and influencing factors of green innovation efficiency in Beijing-Tianjin-Hebei City. Syst. Eng. 2019, 37, 51-61.

30. Peng, R.Z.; Wang, L. Is service industry development green?-Based on total factor efficiency analysis of service industry environment. Ind. Econ. Res. 2016, 4, 18-28.

31. Peng, Y.W.; Zou, M.X. Comparative study on evaluation of regional green innovation efficiency in Hunan Province. Econ. Forum $2019,7,37-44$. 